Angelika Königseder

\title{
Walter de Gruyter
}

\author{
Ein Wissenschaftsverlag im Nationalsozialismus
}

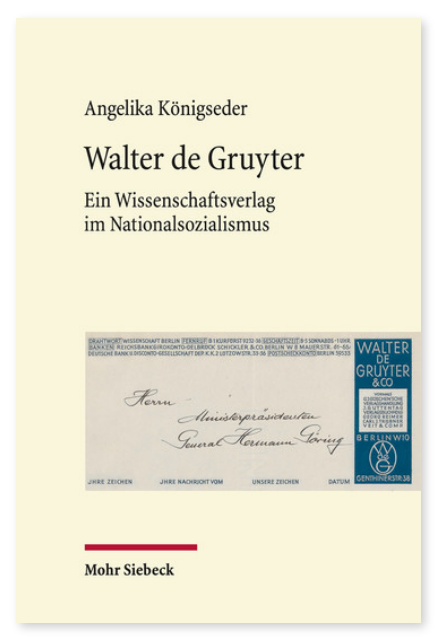

2016. XI, 321 Seiten.

ISBN 978-3-16-154434-7

DOI 10.1628/978-3-16-154434-7

eBook PDF $69,00 €$

ISBN 978-3-16-154393-7

Festeinband $69,00 €$
Der Wissenschaftsverlag Walter de Gruyter agierte während der NS-Herrschaft überaus erfolgreich. Angelika Königseder zeigt, wie er unter der Führung von Herbert Cram die ideologische Neuausrichtung von Staat und Gesellschaft akzeptierte, daran partizipierte und erheblich davon profitierte. Der deutschnational gesinnte Herbert Cram war kein Nationalsozialist, das hinderte inn aber nicht daran, sich als Verleger mit den neuen Machthabern zu arrangieren. Der Verlag bemühte sich einerseits darum, die Qualitätsstandards eines wissenschaftlichen Universalverlages aufrecht zu erhalten, suchte aber zugleich die Nähe zu staatlichen Institutionen und dort angesehenen Wissenschaftlern. Er trennte sich in vorauseilendem Gehorsam von jüdischen und politisch missliebigen Autoren und Herausgebern, ohne vorhandene Handlungsspielräume zu nutzen. Wenn Autoren dem ökonomischen Erfolg eines Projektes im Wege zu stehen schienen, rückte der Verlag von ihnen ab. Die Geschäftspolitik des Verlages Walter de Gruyter unterschied sich damit nicht von der vieler anderer mittelständischer Unternehmen im nationalsozialistischen Deutschland.

Angelika Königseder Geboren 1966; 1991-2010 in verschiedenen Projekten am Zentrum für Antisemitismusforschung, TU Berlin; 2011-19 freiberuflich als Historikerin, Lektorin und Kuratorin von Ausstellungen zur NS-Zeit; seit 2020 Forschungs- und Projektkoordinatorin des Arthur Langerman Archivs für die Erforschung des visuellen Antisemitismus am Zentrum für Antisemitismusforschung, TU Berlin.

Jetzt bestellen:

https://mohrsiebeck.com/buch/walter-de-gruyter-9783161544347?no_cache=1

order@mohrsiebeck.com

Telefon: +49 (0)7071-923-17

Telefax: +49 (0)7071-51104 